\title{
Molecular modelling of tantalum in an aqueous phase
}

\author{
by M.J. Ungerer*, C.G.C.E. van Sittert*, \\ D.J. van der Westhuizen*, and H.M. Krieg*
}

\section{Synopsis}

The transition metals tantalum (Ta) and niobium $(\mathrm{Nb})$ are of significant importance, for example in the nuclear energy sector where they are used as cladding materials, as well as in capacitors and specialized materials. For these applications a high-purity metal is needed. The separation of Ta and $\mathrm{Nb}$ is always a challenge since they are found together in nature and have similar chemical and physical properties, resulting in costly and laborious separation processes. A technology that has been used successfully for the separation of these metals entails solvent extraction $(\mathrm{SX})^{1}$. While separation was achieved in a previous SX study using a sulphuric acid $\left(\mathrm{H}_{2} \mathrm{SO}_{4}\right)$ medium with the extractants diiso-octyl phosphinic acid (PA) and di-(2-ethylhexyl) phosphoric acid (D2EHPA), due to the absence of speciation data for $\mathrm{Ta}$ and $\mathrm{Nb}$ it is not clear how the separation occurred.

One method that might be suitable for determining the speciation of a reaction is molecular modelling. Calculations based on the densityfunctional theory (DFT) are now used not only for light elements and small molecules, but also metal complexes, heavy metals, and especially metal separation in $\mathrm{SX}^{2}$. In this study the aqueous phase used during SX was investigated by studying periodic systems of $\mathrm{Ta}$, as a metal and in salt form, when it is in contact with $\mathrm{H}_{2} \mathrm{O}$ and $\mathrm{H}_{2} \mathrm{SO}_{4}$. The results were used to predict the reaction mechanism occurring during SX. Results showed that (i) in a 1:1 acid-water ratio, the deprotonation of $\mathrm{H}_{2} \mathrm{SO}_{4}$ was endothermic, (ii) in a 1:5 ratio deprotonation was exothermic forming $\mathrm{HSO}_{4}^{-}$, and (iii) in a 1:10 ratio double deprotonation occurred to form $\mathrm{SO}_{4}{ }^{2-}$ exothermically.

Keywords

tantalum, niobium, solvent extraction, reaction mechanism, molecular modelling. to find a cost-effective way to separate Ta and $\mathrm{Nb}$.

Solvent extraction (SX) is used for the separation and purification of various metals, including copper (Bidari, Irannejad, and Gharabaghi, 2013), nickel (Noori et al., 2014), iron (Li et al., 2011), platinum group metals (PGMs) (Kumar et al., 2008), zirconium (Biswas and Hayat, 2002), hafnium (Lee, Banda, and Min, 2015), and $\mathrm{Ta}$, and $\mathrm{Nb}$ (Zhu and Cheng, 2011). Ungerer et al. (2014) studied the separation of $\mathrm{Ta}$ and $\mathrm{Nb}$ (in the form of $\mathrm{MF}_{5}$ ) by SX using safer and more environmentally friendly chemicals and techniques. Although partial separation was achieved in a sulphuric acid $\left(\mathrm{H}_{2} \mathrm{SO}_{4}\right)$ medium with the extractants diiso-octyl phosphinic acid (PA) and di-(2-ethylhexyl) phosphoric acid (D2EHPA), the main obstacle remained the lack of data on the speciation of $\mathrm{Ta}$ and $\mathrm{Nb}$ compounds, without which it was not possible to fully explain the separation data obtained.

One method that could be used for speciation of the compounds is computational methods for SX, which entails a step-by-step analysis of the extraction process on a molecular level and determination of the molecular reactions occurring during SX from a thermodynamic perspective, which could lead to the development of a new method for the analysis of $\mathrm{Ta}$ and $\mathrm{Nb}$ separation by SX.

${ }^{1}$ Narbutt, J. and Czerwinski, M. 1992. Computational chemistry in modelling solvent extraction of metal ions Solvent Extraction Principles and Practice. Rydberg, J., Cox, M., Musikas, C., and Choppin, G.R. (eds). Wiley, New York. Chapter 16

${ }^{2}$ Ungerer, M.J., van der Westhuizen, D.J., Lachmann, G., and Krieg, H.M. 2014. Comparison of extractants for the separation of TaF5 and NbF5 in different acidic media. Hydrometallurgy, vol. 144-145. pp. 195-206.

* Chemical Resource Beneficiation (CRB), NorthWest University, Potchefstroom, South Africa.

(c) The Southern African Institute of Mining and Metallurgy, 2017. ISSN 2225-6253. Paper received Apr. 2016; revised paper received Sept. 2016. 


\section{Molecular modelling of tantalum in an aqueous phase}

In this study we propose the use of molecular modelling to determine the behaviour of $\mathrm{Ta}$ in a sulphuric acid medium. Reactions of $\mathrm{H}_{2} \mathrm{SO}_{4}$ and water (Equations [1] and [2]) and $\mathrm{TaF}_{5}$ in $\mathrm{H}_{2} \mathrm{SO}_{4}$ (Equations [3] and [4]) were investigated.

$$
\begin{aligned}
& \mathrm{H}_{2} \mathrm{SO}_{4}+\mathrm{H}_{2} \mathrm{O} \rightarrow \mathrm{HSO}_{4}^{-}+\mathrm{H}_{3} \mathrm{O}^{+} \\
& \mathrm{HSO}_{4}^{-}+\mathrm{H}_{2} \mathrm{O} \rightarrow \mathrm{SO}_{4}{ }^{2-}+\mathrm{H}_{3} \mathrm{O}^{+} \\
& \mathrm{TaF}_{5}+\mathrm{H}_{2} \mathrm{SO}_{4}+\mathrm{H}_{2} \mathrm{O} \rightarrow \mathrm{TaF}_{5} \cdot \mathrm{HSO}_{4}^{-}+\mathrm{H}_{3} \mathrm{O}^{+} \\
& \mathrm{TaF}_{5}+\mathrm{H}_{2} \mathrm{SO}_{4} \rightarrow \mathrm{TaF}_{4} \cdot \mathrm{HSO}_{4}+\mathrm{HF}
\end{aligned}
$$

\section{Computational methods}

For the molecular modelling of $\mathrm{H}_{2} \mathrm{SO}_{4}$ with $\mathrm{H}_{2} \mathrm{O}$ (Equations [1] and [2]) as well as $\mathrm{TaF}_{5}$ with $\mathrm{H}_{2} \mathrm{SO}_{4}$ (Equations [3] and [4]), both in an aqueous phase, the DMol3 module - a density functional theory (DFT) (Hohenberg and Kohn, 1964; Levy, 1979) quantum mechanical modelling method of the Materials Studio 6.1 software from Accelrys (2012) was used. For all the calculations on the different molecules, a geometry optimization (Perdew and Wang, 1992; Delley, 1992) was first performed with the generalized gradientcorrected approximation (GGA) with Perdew-Wang (1992) correlation functional (PW91). The basis set used was DNP (double-numeric polarization functions) with basis file 4.4 and OBS dispersion correction. The core treatment parameter was set to 'All Electron' and therefore all the calculations were done for the electrons as if they are valence electrons. Under the electronic properties, smearing of 0.005 Hartree (Ha) was also chosen (Delley, 1995) and the solvation model COSMO (conductor-like screening model) (Delley, 2006) was used, with water as the solvent with a dielectric constant of 78.54. COSMO was used to account for the surrounding of implicit $\mathrm{H}_{2} \mathrm{O}$ molecules. After the geometry optimization, various properties were calculated using single-point energy calculations with the same settings as stated previously. The calculations were done in the aqueous phase at $0 \mathrm{~K}$ and the energy correction term was added to give Gibbs free energy values at $298.15 \mathrm{~K}$.

\section{Results and discussion}

The relative energies for Reactions [1] and [2] are presented in Figure 1, where the dotted line represents the reaction energies when using a $1: 1 \mathrm{H}_{2} \mathrm{SO}_{4}: \mathrm{H}_{2} \mathrm{O}$ ratio and the solid line when using a $1: 5 \mathrm{H}_{2} \mathrm{SO}_{4}: \mathrm{H}_{2} \mathrm{O}$ ratio, where five explicit water molecules were added. For each line three points are presented, the first being the energy of the starting materials, the second the energy of the intermediate products, and the third the energy of the final products. When using a 1:1 $\mathrm{H}_{2} \mathrm{SO}_{4}: \mathrm{H}_{2} \mathrm{O}$ ratio (dotted line) it can be seen that when one $\mathrm{H}_{2} \mathrm{SO}_{4}$ molecule reacted consecutively with two $\mathrm{H}_{2} \mathrm{O}$ molecules to firstly form $\mathrm{HSO}_{4}{ }^{-}$and $\mathrm{H}_{3} \mathrm{O}^{+}$, and then $\mathrm{SO}_{4}{ }^{2-}$ and $2 \mathrm{H}_{3} \mathrm{O}^{+}, 33.5 \mathrm{~kJ} / \mathrm{mol}$ and $153.4 \mathrm{~kJ} / \mathrm{mol}$ were needed respectively, indicating an endothermic reaction for both steps.

However, according to laboratory results and values from the literature, Reaction [1] is highly exothermic and Reaction [2] moderately exothermic. Steyl (2009) used DFT modelling (DMol ${ }^{3}$ v.4.2) to show that when $\mathrm{H}_{2} \mathrm{SO}_{4}$ reacted with $\mathrm{H}_{2} \mathrm{O}$, five $\mathrm{H}_{2} \mathrm{O}$ molecules were needed to form an outer sphere around the $\mathrm{H}_{2} \mathrm{SO}_{4}$ molecule to react to form $\mathrm{HSO}_{4}{ }^{-}$. Therefore a balanced reaction equation was modelled where five $\mathrm{H}_{2} \mathrm{O}$ molecules reacted with $\mathrm{H}_{2} \mathrm{SO}_{4}$ as follows:

$$
\begin{aligned}
& \mathrm{H}_{2} \mathrm{SO}_{4}+5 \mathrm{H}_{2} \mathrm{O} \rightarrow \mathrm{HSO}_{4}{ }^{-}+\mathrm{H}_{3} \mathrm{O}^{+}+4 \mathrm{H}_{2} \mathrm{O} \\
& \mathrm{HSO}_{4}^{-}+4 \mathrm{H}_{2} \mathrm{O} \rightarrow \mathrm{SO}_{4}{ }^{2-}+2 \mathrm{H}_{3} \mathrm{O}^{+}+3 \mathrm{H}_{2} \mathrm{O}
\end{aligned}
$$

According to Figure 1 (solid line) the reaction becomes exothermic, as expected, when sufficient water molecules are available. To determine the effect of adding further water molecules it was decided to model the $\mathrm{H}_{2} \mathrm{SO}_{4}-\mathrm{H}_{2} \mathrm{O}$ system with 10 explicit waters surrounding the acid (Figure 1 dashed line). After the geometry optimization of the 1:10 system, it was seen that double deprotonation of $\mathrm{H}_{2} \mathrm{SO}_{4}$ took place, without the formation of $\mathrm{HSO}_{4}{ }^{-}$as an intermediate step. The energy decrease to $-816 \mathrm{~kJ} / \mathrm{mol}$ indicates an exothermic reaction with a stabilized ion forming as the final product. As when using five $\mathrm{H}_{2} \mathrm{O}$ molecules, the surrounding $\mathrm{H}_{2} \mathrm{O}$ molecules stabilized the ion by hydrogen bonding. Ding and Laasonen (2004), using DFT modelling with PW91(DNP) as well as BLYP calculations, showed that when less than five $\mathrm{H}_{2} \mathrm{O}$ molecules are present with $\mathrm{H}_{2} \mathrm{SO}_{4}$ the first deprotonation occurs exothermically, and when eight to ten $\mathrm{H}_{2} \mathrm{O}$ molecules surround $\mathrm{H}_{2} \mathrm{SO}_{4}$, the second deprotonation also occurs, resulting in the formation of $\mathrm{SO}_{4}{ }^{2-}$ with the other surrounding $\mathrm{H}_{2} \mathrm{O}$ molecules forming hydrogen bonds and stabilizing the formed ions. Hammerich, Buch, and Mohamed (2008) used ab initio modelling methods and also showed that when ten $\mathrm{H}_{2} \mathrm{O}$ molecules are present double deprotonation occurs, but also observed proton hopping between the different oxygen sites of $\mathrm{HSO}_{4}{ }^{-}$and the surrounding $\mathrm{H}_{2} \mathrm{O}$ molecules. Although it is generally assumed that $\mathrm{H}_{2} \mathrm{SO}_{4}: \mathrm{H}_{2} \mathrm{O}$ is a $1: 1$ reaction, it was shown that, energetically, from five to ten explicit $\mathrm{H}_{2} \mathrm{O}$ molecules are needed for the reaction to occur. According to these results, the $1: 10$ reaction of $\mathrm{H}_{2} \mathrm{SO}_{4}$ in $\mathrm{H}_{2} \mathrm{O}$ showed the best correlation to the real system.

In the second part of the investigation, the reaction of $\mathrm{TaF}_{5}$ and $\mathrm{H}_{2} \mathrm{SO}_{4}$ in the presence of 1,5 and $10 \mathrm{H}_{2} \mathrm{O}$ molecules was modelled at $\mathrm{TaF}_{5}: \mathrm{H}_{2} \mathrm{SO}_{4}: \mathrm{H}_{2} \mathrm{O}$ ratios of $1: 1: 1,1: 1: 5$, and 1:1:10. Since $\mathrm{TaF}_{5}$ has a trigonal bipyramidal structure, the $\mathrm{H}_{2} \mathrm{SO}_{4}$ molecule will most likely approach from an equatorial position (where more space and best orbital overlap is available) to form $\mathrm{TaF}_{5} \cdot \mathrm{HSO}_{4}{ }^{-}$(octahedral structure) before rearranging to $\mathrm{TaF}_{4} \cdot \mathrm{HSO}_{4}$, where the $\mathrm{HSO}_{4}{ }^{-}$group can be either axial or equatorial (Figure 2).

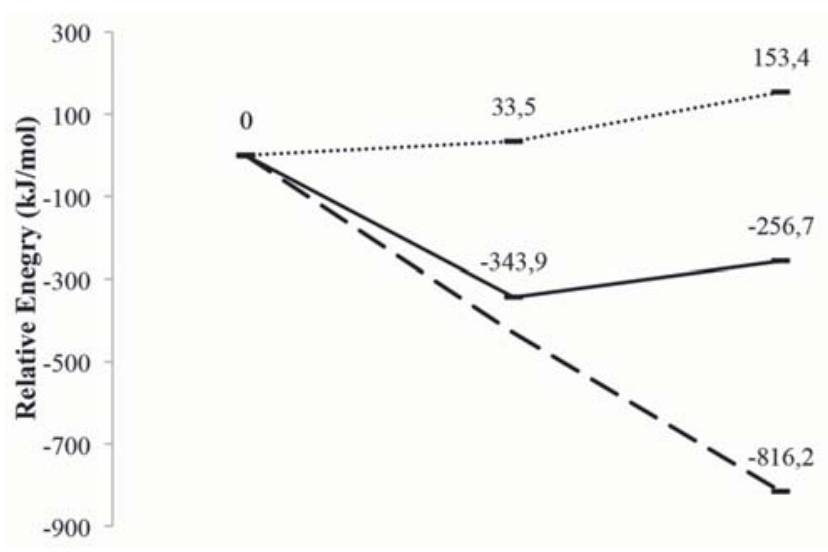

Figure 1-Relative reaction energy (kJ/mol) for $\mathrm{H}_{2} \mathrm{SO}_{4}$ and $\mathrm{H}_{2} \mathrm{O}$ (dotted line is $\mathrm{H}_{2} \mathrm{SO}_{4}: \mathrm{H}_{2} \mathrm{O}=1: 1$; solid line is $\mathrm{H}_{2} \mathrm{SO}_{4}: \mathrm{H}_{2} \mathrm{O}=1: 5$; dashed line is $\mathrm{H}_{2} \mathrm{SO}_{4}: \mathrm{H}_{2} \mathrm{O}=1: 10$ ) 


\section{Molecular modelling of tantalum in an aqueous phase}

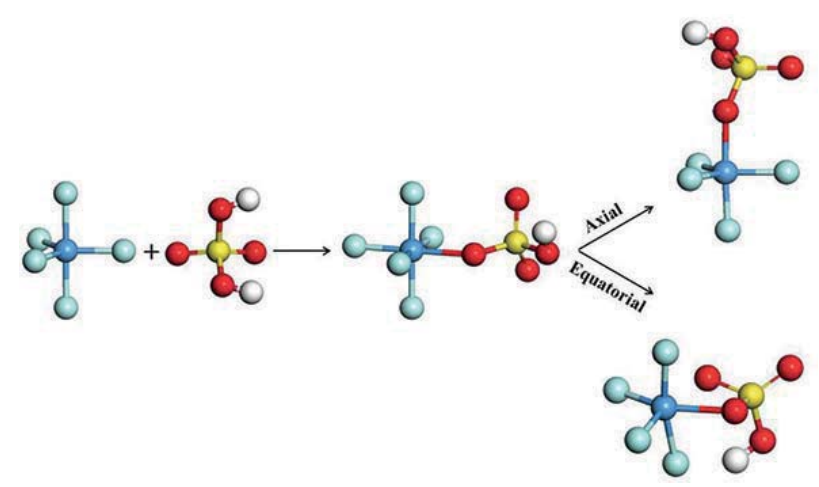

Figure 2-Possible reaction pathway of $\mathrm{TaF}_{5}$ and $\mathrm{H}_{2} \mathrm{SO}_{4}$

As with Equations [1] and [2], it was expected that the relative reaction energies would be lower when adding explicit water molecules to Equations [3] and [4]. To confirm this, the same calculations done for Equations [1] and [2] were performed for Equations [3] and [4]. The relative energies of the reactions of $\mathrm{TaF}_{5}$ with $\mathrm{H}_{2} \mathrm{SO}_{4}$ and $\mathrm{H}_{2} \mathrm{O}$ are shown in Figure 3. The dotted line shows the energies for a $\mathrm{TaF}_{5}: \mathrm{H}_{2} \mathrm{SO}_{4}: \mathrm{H}_{2} \mathrm{O}$ ratio of $1: 1: 1$, the solid line the energies for a $\mathrm{TaF}_{5}: \mathrm{H}_{2} \mathrm{SO}_{4}: \mathrm{H}_{2} \mathrm{O}$ ratio of $1: 1: 5$, and the dashed lines the energies when the $\mathrm{TaF}_{5}: \mathrm{H}_{2} \mathrm{SO}_{4}: \mathrm{H}_{2} \mathrm{O}$ ratio is $1: 1: 10$. Again, the first data point is the energy of the reagents, the second the energy of the intermediates, and the third the energy of the products.

As shown in Figure 2, the position of the $\mathrm{HSO}_{4}{ }^{-}$group can be either axial or equatorial. In Figure 3, for the 1:1:1 reaction (dotted line) $105 \mathrm{~kJ} / \mathrm{mol}$ is needed for the $\mathrm{HSO}_{4}$ group to bond to $\mathrm{TaF}_{5}$, before $\mathrm{HF}$ is evolved and $\mathrm{TaF}_{4} \cdot \mathrm{HSO}_{4}$ is formed at $97.2 \mathrm{~kJ} / \mathrm{mol}$ and $54.4 \mathrm{~kJ} / \mathrm{mol}$ for the axial and equatorial positions respectively, indicating an endothermic reaction. However when using more $\mathrm{H}_{2} \mathrm{O}$ (five molecules solid line) $-304.8 \mathrm{~kJ} / \mathrm{mol}$ is needed to form $\mathrm{TaF}_{5} \cdot \mathrm{HSO}_{4}{ }^{-}$, indicating that a stable ion forms. The formation of $\mathrm{TaF}_{4} \cdot \mathrm{HSO}_{4}$ in the axial position requires $-158.6 \mathrm{~kJ} / \mathrm{mol}$, and in the equatorial position $-203.5 \mathrm{~kJ} / \mathrm{mol}$, indicating an exothermic reaction. The same trend was observed as for the 1:1:1 reaction, where the molecule with the $\mathrm{HSO}_{4}{ }^{-}$group in the equatorial position was at a lower energy than when the group is axial. This is due to the orbital overlap that occurs between the $\mathrm{HSO}_{4}{ }^{-}$group and $\mathrm{TaF}_{5}$ when the reaction takes place. Steyl (2009) obtained similar results.

The 1:1:10 reaction of $\mathrm{TaF}_{5}: \mathrm{H}_{2} \mathrm{SO}_{4}: \mathrm{H}_{2} \mathrm{O}$ was also modelled. Again, the $\mathrm{HSO}_{4}{ }^{-}$ion bonded axially and equatorially, and as with the $1 \mathrm{H}_{2} \mathrm{SO}_{4}: 10 \mathrm{H}_{2} \mathrm{O}$ system, double deprotonation occurred. The intermediate molecule $\mathrm{TaF}_{4} \cdot \mathrm{HSO}_{4}$ did not form, but the $\mathrm{TaF}_{4} \mathrm{SO}_{4}{ }^{-}$molecule formed and was stabilized by the surrounding $\mathrm{H}_{3} \mathrm{O}^{+}$ions and $\mathrm{H}_{2} \mathrm{O}$ molecules. This would imply that the 1:1:10 reaction scheme had the lowest energy and would therefore be energetically the most likely.

Furthermore, it was seen from the modelling results that when the $\mathrm{HSO}_{4}{ }^{-}$group was in the equatorial position it formed a bidentate bond to $\mathrm{Ta}$, lowering the overall energy of the molecule and changing the oxidation state of Ta from $5+$ to $4+$ in both the $1: 5$ and the $1: 10$ system.

\section{Conclusion}

The reactions of $\mathrm{H}_{2} \mathrm{SO}_{4}$ with $\mathrm{H}_{2} \mathrm{O}$ and $\mathrm{TaF}_{5}$ with $\mathrm{H}_{2} \mathrm{SO}_{4}$ and $\mathrm{H}_{2} \mathrm{O}$ were investigated. When modelling a $1: 1$ reaction of acid and water an endothermic reaction was observed. The modelling software COSMO was used to account for the surrounding implicit $\mathrm{H}_{2} \mathrm{O}$ molecules. By adding five explicit $\mathrm{H}_{2} \mathrm{O}$ molecules to the reaction, an exothermic reaction was observed for the reactions of $\mathrm{H}_{2} \mathrm{SO}_{4}$ with $\mathrm{H}_{2} \mathrm{O}$. This indicated that COSMO adds a correction term for the long-range interactions that could occur if these reactions occurred in water as a medium, but does not show or calculate the explicit reactions and hydrogen bonding that occur with $\mathrm{H}_{2} \mathrm{O}$ in the short range. This hydrogen bonding stabilizes the molecules, resulting in lower energy values. With the addition of 10 explicit $\mathrm{H}_{2} \mathrm{O}$ molecules a double deprotonation was observed with the formation of $\mathrm{SO}_{4}{ }^{2-}$ stabilized by the surrounding hydrogen bonds. The same tendencies were observed for the reactions of $\mathrm{TaF}_{5}$ with $\mathrm{H}_{2} \mathrm{SO}_{4}$ and $\mathrm{H}_{2} \mathrm{O}$, where the explicit $\mathrm{H}_{2} \mathrm{O}$ molecules lowered the overall reaction energies, showing an exothermic reaction. The resulting ions were stabilized with the surrounding $\mathrm{H}_{3} \mathrm{O}^{+}$ions and $\mathrm{H}_{2} \mathrm{O}$ molecules.

Further investigations are needed to determine the side reactions and other geometries that may occur during these reactions, as well as the possible influence if a change in oxidation state occurs.

\section{Acknowledgements}

The author would like to thank the South African Nuclear Energy Corporation SOC Limited (Necsa) and the New Metals Development Network (NMDN) of the Advanced Metals Initiative (AMI) of the Department of Science and Technology (DST) for financial support, and the North-West University High Performance Computing (NWU-HPC) centre for the use of their facilities and their support.

\section{References}

ACCELRYS SOFTWARE Inc. 2012. Material Studio Modelling Environment, version 6.1. San Diego.

Agulyanski, A. 2004. The chemistry of tantalum and niobium fluoride compounds. Elsevier, San Diego, Oxford, London.

BidARI, E., IRANNejAD, M., and GHARABAGHI, M. 2013. Solvent extraction recovery and separation of cadmium and copper from sulphate solution. Journal of Environmental Chemical Engineering, vol. 1. pp. 1269-1274.

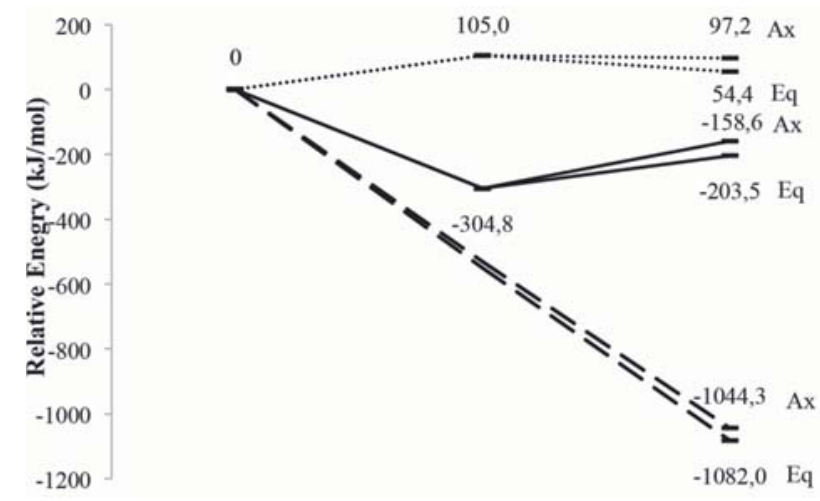

Figure 3-Relative reaction energy ( $\mathrm{kJ} / \mathrm{mol}$ ) for $\mathrm{TaF}_{5}, \mathrm{H}_{2} \mathrm{SO}_{4}$, and $\mathrm{H}_{2} \mathrm{O}$ (dotted line is $1: 1: 1$ reaction, solid line is $1: 1: 5$ reaction, dashed line is $\mathrm{H}_{2} \mathrm{SO}_{4}: \mathrm{H}_{2} \mathrm{O}=1: 1: 10$ ) 


\section{Molecular modelling of tantalum in an aqueous phase}

BISWAS, R.K. and HAYAT, M.A. 2002. Solvent extraction of zirconium(IV) from chloride media by D2EHPA in kerosene. Hydrometallurgy, vol. 63. pp. 149-158.

DeLLEY, B. 1992. Ground-state enthalpies: evaluation of electronic structure approaches with emphasis on the density functional method. Journal of Physical Chemistry A, vol. 110. pp. 13632-13639.

Delley, B., and ScherRer, P. 1995. DMol, a standard tool for density functional calculations: review and advances Modern Density Functional Theory: a Tool for Chemistry. Seminario, J.M. and Politzer, P. (eds). Theoretical and Computational Chemistry Series, vol. 2. Elsevier.

DelLey, B. 2006. The conductor-like screening model for polymers and surfaces. Molecular Simulation, vol. 32. pp. 117-123.

Ding, C.G., and LAASONEN, K. 2004. Partially and fully deprotonated sulfuric acid in $\mathrm{H}_{2} \mathrm{SO}_{4}\left(\mathrm{H}_{2} \mathrm{O}\right)_{\mathrm{n}}(\mathrm{n}=6$ - 9) clusters. Chemical Physics Letters, vol. 390. pp. 307-313.

Hammerich, A.D., Buch, V., and Mohamed, F. 2008. Ab initio simulations of sulfuric acid solutions. Chemical Physics Letters, vol. 460. pp. 423-431.

HohenBerg, P. and KoHn, W. 1964. Inhomogeneous electron gas. Physical Review B, vol. 136. p. B864

KREBS, R.E. 2006. The History and Use of Our Earth's Chemical Elements: A Reference Guide. 2nd edn. Greenwood Press, Westport, USA

Kumar, J.R., LeE, H.I., LeE, J.Y., KIM, J.S., and Sohn, J.S. 2008. Comparison of liquid-liquid extraction studies on platinum(IV) from acidic solutions using bis(2,4,4-trimethylpentyl) monothiophosphinic acid. Separation and Purification Technology, vol. 63. pp. 184-190.

LeE, M.S., BANDA, R., and Min, S.H. 2015. Separation of $\mathrm{Hf}(\mathrm{IV})-\mathrm{Zr}(\mathrm{IV})$ in $\mathrm{H}_{2} \mathrm{SO}_{4}$ solutions using solvent extraction with D2EHPA or Cyanex 272 at different reagent and metal ion concentrations. Hydrometallurgy, vol. 152. pp. 84-90.
LeVY, M. 1979. Universal variational functionals of electron densities, firstorder density matrices, and natural spin-orbitals ans solution of the vrepresentability problem. Proceedings of the National Academy of Sciences, vol. 76. pp. 6062-6065.

LI, X., Wei, C., Deng, Z., LI, M., LI, C., and Fan, G. 2011. Selective solvent extraction of vanadium over iron from a stone coal/black shale acid leach solution by D2EHPA/TBP. Hydrometallurgy, vol. 105. pp. 359-363.

NARBUTT, J. and CZERwinsKi, M. 1992. Computational chemistry in modelling solvent extraction of metal ions. Solvent Extraction Principles and Practice. Rydberg, J., Cox, M., Musikas, C., and Choppin, G.R. (eds.). Wiley, New York. Chapter 16.

NooRi, M., RASHCHI, F., BABAKHANI, A., and VAHIDI, E. 2014. Selective recovery and separation of nickel and vanadium in sulfate media using mixtures of D2EHPA and Cyanex 272. Separation and Purification Technology, vol. 136. pp. 265-273.

Perdew, J.P., and WANG, Y. 1992. Accurate and simple analytic representation of the electron-gas correlation energy. Physical Review B, vol. 45. pp. 13244-13249.

STEYL, J.D.T. 2009. Kinetic modelling of chemical processes in acid solution at $\mathrm{t} \leq 200^{\circ} \mathrm{C}$. (i) thermodynamics and speciation in $\mathrm{H}_{2} \mathrm{SO}_{4}$-metal (ii) $\mathrm{SO}_{4}-\mathrm{H}_{2} \mathrm{O}$ system. Proceedings of Hydrometallurgy 2009, Misty Hills, Muldersdrift, Gauteng 24-26 February. Southern African Institute of Mining and Metallurgy, Johannesburg. pp. 401-444.

Ungerer, M.J., van der Westhuizen, D.J., Lachmann, G., and Krieg, H.M. 2014. Comparison of extractants for the separation of $\mathrm{TaF}_{5}$ and $\mathrm{NbF}_{5}$ in different acidic media. Hydrometallurgy, vol. 144-145. pp. 195-206.

ZHu, Z. and CHENG, C.Y. 2011. Solvent extraction technology for the separation and purification of niobium and tantalum: a review. Hydrometallurgy, vol. 108. pp. 1-12.

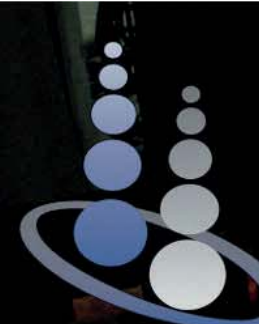

AM Applied Engineering and Construction
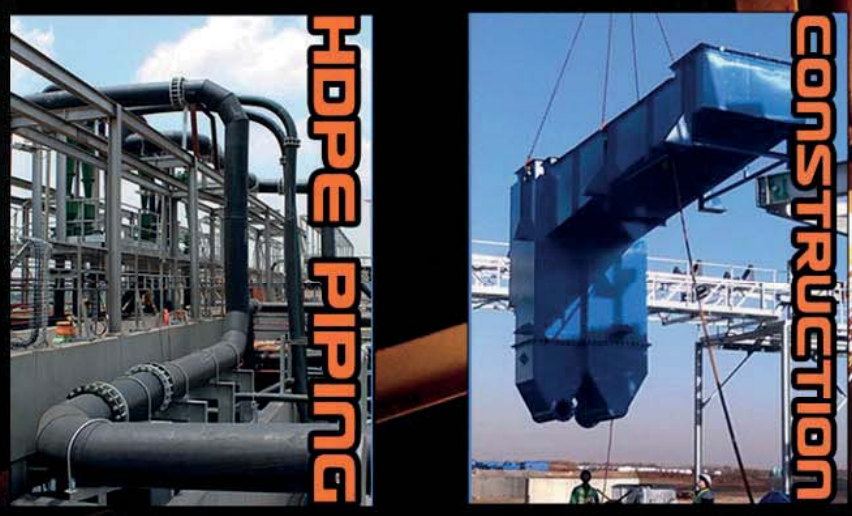

(1)

용 0136502270

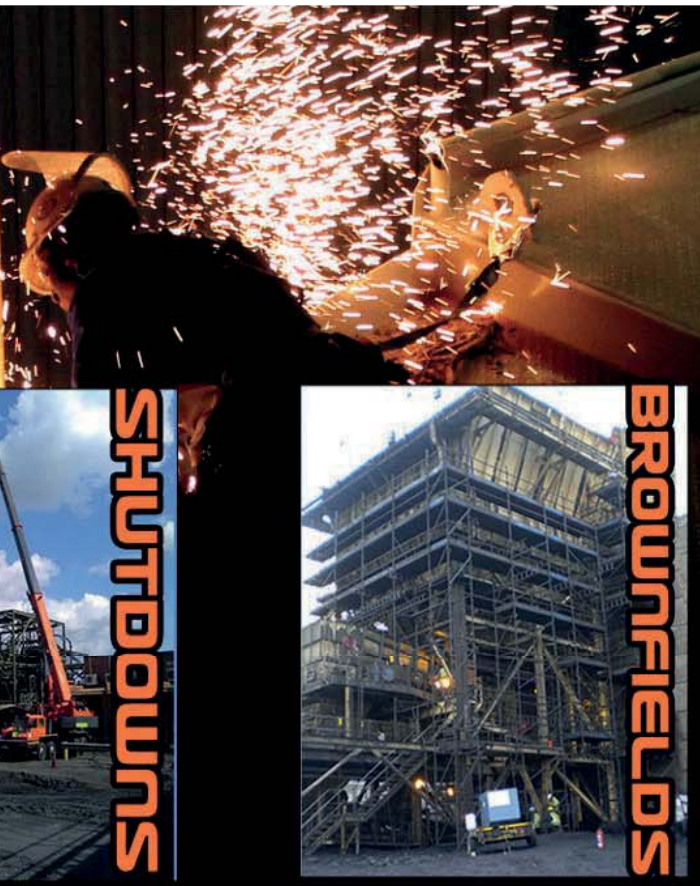

ewww.amtec.co.za 